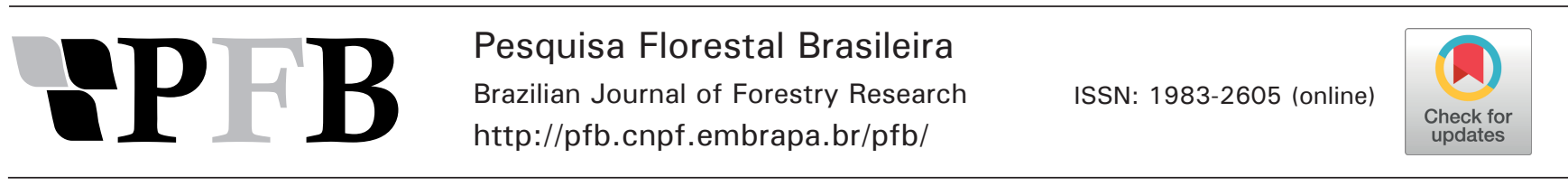

\title{
Estratégias fenológicas de Byrsonima basiloba em Rio Verde, Goiás, Brasil
}

\author{
Patrícia Oliveira da Silva ${ }^{1 *}$, Cristiane Libindo Balestra ${ }^{2}$, Michellia Pereira Soares $^{3}$, Gisele Cristina de Oliveira Menino ${ }^{1}$ \\ ${ }^{1}$ Instituto Federal Goiano, Rodovia Sul Goiana, s/n, C P 66, CEP 75901-970, Rio Verde, GO, Brasil \\ ${ }^{2}$ Instituto Superior de Educação Almeida Rodrigues, Rua Quinca Honório Leão, 1030, CEP 75909-030, Rio Verde, GO, Brasil \\ ${ }^{3}$ Instituto Federal de Educação, Ciência e Tecnologia do Norte de Minas Gerais, Rodovia Salinas/Taiobeiras, Km 2, CEP 39560-000, Salinas, MG, Brasil
}

*Autor correspondente:

patyoliveira1919@hotmail.com

Termos para indexação:

Ecologia vegetal

Reprodução vegetativa

Fruta tropical

Index terms:

Plant ecology

Asexual reproduction

Tropical fruit

Histórico do artigo:

Recebido em 27/07/2015

Aprovado em 12/09/2016

Publicado em 30/09/2016

doi: 10.4336/2016.pfb.36.87.989

\begin{abstract}
Resumo - Este estudo descreve pela primeira vez a fenologia de Byrsonima basiloba. Foram observadas mensalmente as fenofases reprodutivas e vegetativas em 15 indivíduos. Para a coleta e análise dos dados utilizou-se o percentual de Fournier e a porcentagem de indivíduos. Posteriormente, os dados foram correlacionados às variáveis climáticas. Os espécimes de $B$. basiloba floresceram na época chuvosa e de maneira sincrônica, se correlacionando com a pluviosidade e umidade. A frutificação ocorreu na transição do período seco para o chuvoso, também de maneira sincrônica e correlacionada com a temperatura. Observou-se a maturação dos frutos na estação seca, semelhante à senescência que apresentou correlação com a precipitação. $\mathrm{O}$ enfolhamento ocorreu na transição do período seco para o chuvoso, resultando na correlação com a pluviosidade e a temperatura. A folhagem adulta esteve presente durante todo o estudo e se correlacionou com a precipitação e umidade. A espécie estudada apresenta comportamento reprodutivo distinto das espécies do mesmo gênero, mas semelhantes a outras espécies do Cerrado, enquanto que os aspectos vegetativos são comuns ao gênero Byrsonima.
\end{abstract}

\section{Phenological strategies of Byrsonima basiloba in Rio Verde, Goias State, Brazil}

\begin{abstract}
This study describes for the first time the phenology of Byrsonima basiloba. Reproductive and vegetative phenophases of 15 individuals were observed monthly. To collect and analyze the data we used the percentage of Fournier and the percentage of individuals and then the data were correlated to climatic variables. B. basiloba trees flourished synchronously in the wet season, correlating with rainfall and humidity. Fruiting occurred also synchronous in the transition from wet to dry season and correlated with temperature. Fruits ripening occurred mainly in the dry season and senescence was recorded also in the dry season, correlating with precipitation. The leafiness occurred in the transition from dry to rainy season resulting in correlation with rainfall and temperature. The mature foliage was present throughout the study and correlated with precipitation and humidity. The specimens presents different reproductive pattern from other Byrsonima specimens, but similar to other species from Cerrado, while vegetative aspects are common to the genre Byrsonima.
\end{abstract}

\section{Introdução}

A família botânica Malpighiaceae apresenta espécies de grande importância em todo o mundo, além de ser uma das dez mais frequentes no Cerrado brasileiro (Mendonça et al., 1998). É representada por 75 gêneros e 1.300 espécies, com distribuição tropical e subtropical (Souza \& Lorenzi, 2008). No Brasil, ocorrem 38 gêneros e aproximadamente 300 espécies, as quais apresentam grande potencial econômico, como fonte de produtos alimentícios, medicinais, madeireiros, ornamentais, dentre outros (Ribeiro et al., 1999).

Dentre os 75 gêneros, Byrsonima é o maior da família Malpighiaceae (Ribeiro et al., 1999; Judd et al., 2002) e estima-se que o mesmo possua mais de 200 espécies, 
sendo que 100 delas estão amplamente distribuídas no país. Uma das espécies de grande ocorrência no Brasil é Byrsonima basiloba, podendo ser encontrada em diversas fisionomias do Cerrado, entre elas: campo sujo, campo limpo, cerrado sensu stricto e até em campo rupestre (Medeiros, 2011).

B. basiloba possui hábito arbustivo, folhas simples, discolores e pilosas, cujos frutos também são chamados de murici-de-ema (Farias et al., 2002). As flores de B. basiloba são amarelas, bissexuais, pentâmeras, dialipétalas, com nectários extraflorais, dispostas em rácemos terminais curtos e, de acordo com Silva et al. (2012), sua polinização ocorre através de abelhas. Segundo Lorenzi (2008), sua floração ocorre quase o ano inteiro, predominantemente durante o verão e a maturação dos frutos com maior intensidade de abril a junho. A taxa de germinação desta espécie é considerada baixa. A emergência ocorre de 40-60 dias e seu crescimento é lento.

Vários trabalhos descrevendo os aspectos da biologia reprodutiva são encontrados para as espécies do gênero Byrsonima, como B. crassifolia (Pereira \& Freitas, 2002), B. cripa (Tabarelli, 2004), B. coccolobifolia (Benezar \& Pessoni, 2006), B. gardneriana (Bezerra et al., 2009) e $B$. sericea (Teixeira \& Machado, 2000; Rosa \& Ramalho, 2007). Entretanto, mesmo havendo trabalhos científicos que descrevem os aspectos reprodutivos de espécies do gênero Byrsonima, a espécie $B$. basiloba é praticamente desconhecida. Dessa forma, este estudo descreve pela primeira vez os aspectos fenológicos reprodutivos e vegetativos de uma população de $B$. basiloba localizada no Munícipio de Rio Verde, GO.

\section{Material e métodos}

A área de estudo consiste em um fragmento de Cerrado, que apresenta duas fisionomias, cerradão e cerrado sensu stricto, localizado na Fazenda Fontes do Saber, da Universidade de Rio Verde $\left(17^{\circ} 47^{\prime} 12^{\prime \prime}\right.$ 'S e 5057'48’W), Município de Rio Verde, GO. Segundo a classificação de Köppen, o Domínio Cerrado apresenta clima do tipo Aw (tropical típico), com sazonalidade pronunciada de pluviosidade. O solo é do tipo latossolo vermelho-amarelo, profundo, bem drenado, com alto teor de argila, baixa fertilidade e alta toxidez de alumínio (Haridasan, 1993).

As observações fenológicas foram realizadas em 15 indivíduos de B. basiloba que apresentaram circunferência à altura do peito (CAP) maior que
$30 \mathrm{~cm}$, localizados em fisionomia de cerrado sensu stricto. As árvores foram marcadas com placas de alumínio, numeradas sequencialmente. As observações ocorreram mensalmente, conforme metodologia de Fournier (1974), Fournier \& Charpantier (1975) e Newstrom et al. (1994) entre agosto de 2013 e junho de 2015. Em cada observação registravam-se, a olho nu, as fenofases reprodutivas: botão, flor aberta (antese), fruto imaturo e maduro; e as vegetativas: broto, folha jovem, folha adulta e senescência (Morellato et al., 1989). Para a avaliação das fenofases, utilizou-se o percentual de Fournier (1974), método que estima a intensidade dos eventos individualmente através de uma escala semiquantitativa de cinco categorias (0 a 4), sendo 0 equivalente a $0 \%$; (1) 1 a $25 \%$; (2) 26 a $50 \%$; (3) 51 a $75 \%$ e (4) 76 a $100 \%$.

A sincronia entre os indivíduos da população de $B$. basiloba foi avaliada através do método de presença/ ausência, que indica a porcentagem de indivíduos em cada fenofase. Considerando evento fenológico assincrônico: $<20 \%$ dos indivíduos da população apresentando a fenofase; pouco sincrônico $20-60 \%$ dos indivíduos e muito sincrônico $>60 \%$ de indivíduos (Bencke \& Morellato, 2002).

A correlação de Spearman foi utilizada para verificar se os eventos estudados apresentaram algum tipo de relação com as variáveis climáticas (temperatura em ${ }^{\circ} \mathrm{C}$, $\%$ de umidade relativa do ar e precipitação pluviométrica em $\mathrm{mm}$ ), que foram obtidas do Instituto Nacional de Meteorologia (2015).

\section{Resultados e discussão}

A emissão de botões florais de Byrsonima basiloba foi sazonal, durante a estação chuvosa, nos dois anos de observação. Os botões florais começaram a se formar juntamente com o início do período chuvoso, sendo também registrados na estação seca. Porém, observou-se que os botões produzidos no final da estação chuvosa ou fora do período chuvoso secaram antes de se desenvolverem, comportamento observado para outra espécie de Cerrado (Caryocar brasiliense) em Minas Gerais, por Freitas et al. (2008). O pico de maior intensidade foi registrado após o mês de maior precipitação pluviométrica para ambos os anos de observação (Figura 1-A). Observou-se alta sincronia para este evento (Figura 1-B) nos meses de maiores índices de pluviosidade e umidade relativa do ar, sendo que tais fatores climáticos se mostraram correlacionados 
positivamente com esta fenofase (Tabela 1). O início da floração na estação chuvosa parece ser bastante comum para espécies do Cerrado, sendo observado em Dipteryx alata por Oliveira \& Sigrist (2008), Annona coriacea (Soares et al., 2013) e em Xylopia aromatica (Soares et al., 2014). Segundo Batalha \& Mantovani (2000) esse comportamento pode ser explicado pela reidratação dos tecidos que ocorrem durante as primeiras chuvas após um longo período de estiagem, o que pode favorecer não só a sincronia, mas também uma alta produção em algumas espécies do Cerrado.

Tabela 1. Correlação de Spearman (rs) entre as variáveis climáticas e os índices de atividade e intensidade das fenofases de B. basiloba, agosto de 2013 a junho de 2015.

\begin{tabular}{|c|c|c|c|c|}
\hline & Fenofases & $\begin{array}{l}\text { Precipitação } \\
\text { (mm) }\end{array}$ & $\begin{array}{c}\text { Temperatura } \\
\left({ }^{\circ} \mathrm{C}\right)\end{array}$ & $\begin{array}{c}\text { Umidade } \\
(\%)\end{array}$ \\
\hline \multirow[t]{8}{*}{ Intensidade } & Botão & $0,73^{*}$ & $-0,08$ & $0,60 *$ \\
\hline & Antese & $0,63 *$ & $-0,04$ & $0,47 *$ \\
\hline & $\begin{array}{l}\text { Fruto } \\
\text { Imaturo }\end{array}$ & $-0,12$ & $-0,50 *$ & $-0,02$ \\
\hline & $\begin{array}{l}\text { Fruto } \\
\text { Maduro }\end{array}$ & $-0,64 *$ & $-0,43 *$ & $-0,40 *$ \\
\hline & Broto & $-0,09$ & $0,55^{*}$ & $-0,28$ \\
\hline & Folha Jovem & $0,30 *$ & $0,42 *$ & 0,09 \\
\hline & Folha Adulta & $-0,27 *$ & $-0,17$ & $-0,19 *$ \\
\hline & Senescência & $-0,55^{*}$ & 0,20 & $-0,36$ \\
\hline \multirow[t]{8}{*}{ Atividade } & Botão & $0,70^{*}$ & $-0,10$ & $0,59^{*}$ \\
\hline & Antese & $0,62 *$ & $-0,09$ & $0,44 *$ \\
\hline & $\begin{array}{l}\text { Fruto } \\
\text { Imaturo }\end{array}$ & $-0,09$ & $-0,50 *$ & $-0,02$ \\
\hline & $\begin{array}{l}\text { Fruto } \\
\text { Maduro }\end{array}$ & $-0,64 *$ & $-0,43 *$ & $-0,40^{*}$ \\
\hline & Broto & $-0,08$ & $0,52 *$ & $-0,28$ \\
\hline & Folha Jovem & $0,26^{*}$ & $0,41^{*}$ & 0,06 \\
\hline & Folha Adulta & $-0,52 *$ & $-0,10$ & $-0,52 *$ \\
\hline & Senescência & $-0,56^{*}$ & 0,19 & $-0,36$ \\
\hline
\end{tabular}

Nota:* Valor significativo $\mathrm{p} \leq 0,05$.

A antese também começou no início do período chuvoso, ocorrendo de novembro a abril para ambos os anos de observação. O pico de intensidade para este evento ocorreu em fevereiro de 2014 e janeiro de 2015 (Figura 1-A). Em ambos os anos a antese foi relativamente baixa, quando comparada com a produção de botões. $\mathrm{O}$ evento foi considerado muito sincrônico em todos os meses chuvosos em que se observou floração (Figura 1-B) e, portanto, a antese também se correlacionou positivamente com as mesmas variáveis climáticas que a fenofase de botão, precipitação e umidade (Tabela 1). Diferentemente dos dados obtidos neste estudo, Silvério \& Fernandes-Bulhão (2009) registraram em Mato Grosso para espécies de Byrsonima florescimento em épocas distintas, sendo que apenas $B$. verbascifolia floresceu durante as chuvas, $B$. orbignyana floresceu na transição do período chuvoso para o seco e $B$. crassa floresceu durante toda a estação seca até o início da estação chuvosa. De acordo com Oliveira (2008), o que promove as diferentes épocas de floração do gênero Byrsonima é a competição pelos agentes de polinização, pois as espécies da família Malpighiaceae compartilham os mesmos polinizadores (Anderson, 1979).

A produção de frutos também se iniciou no período chuvoso, embora tenha apresentado maiores concentrações no início da estação seca. Os picos de intensidade ocorreram em abril e março para 2014 e 2015, respectivamente (Figura 1-A). Houve alta sincronia de janeiro a junho para o ano de 2014 e de fevereiro a junho para 2015, porém a frutificação de 2014 foi superior à de 2015 (Figura 1-B). O evento de frutos imaturos foi a única fenofase que apresentou coeficiente de correlação significativo e de modo negativo com a temperatura (Tabela 1). Figueiredo (2008) afirma que quando as espécies arbóreas do Cerrado exibem crescimento e reprodução no final da estação chuvosa e no auge da seca é um indicativo que a fenologia dessas espécies não é limitada pela seca, mas sim por ritmos endógenos induzidos pelas pequenas variações no fotoperíodo, temperatura e irradiação.

Durante a frutificação nos dois anos, foram observados frutos caídos no chão antes mesmo de estarem maduros, em maior concentração no mês de maio. Possivelmente, os frutos estavam sofrendo predação por larvas de insetos, uma vez que os mesmos apresentavam orifícios (Figura 2-A) e manchas na epiderme (Figura 2-B). Alguns apresentavam aspecto de podre, ainda fixos na planta-mãe (Figura 2-C). Benezar \& Pessoni (2006), ao estudar $B$. coccolobifolia, verificaram que os frutos são muito predados por Polistinae sp. (Vespidae), que chegam a ficar até 5 min perfurando-os, sendo também observada predação por hemípteros do gênero Leptoglossus, através da sucção da seiva, tanto de frutos verdes quanto maduros. Além disso, Oliveira (2013) mostra em um estudo realizado em savana amazônica que não só $B$. basiloba, mas também $B$. ligustrifolia e $B$. verbascifolia estão entre as espécies da família Malpighiaceae cujos frutos são utilizados como sítios de criação de drosofilídeos. 


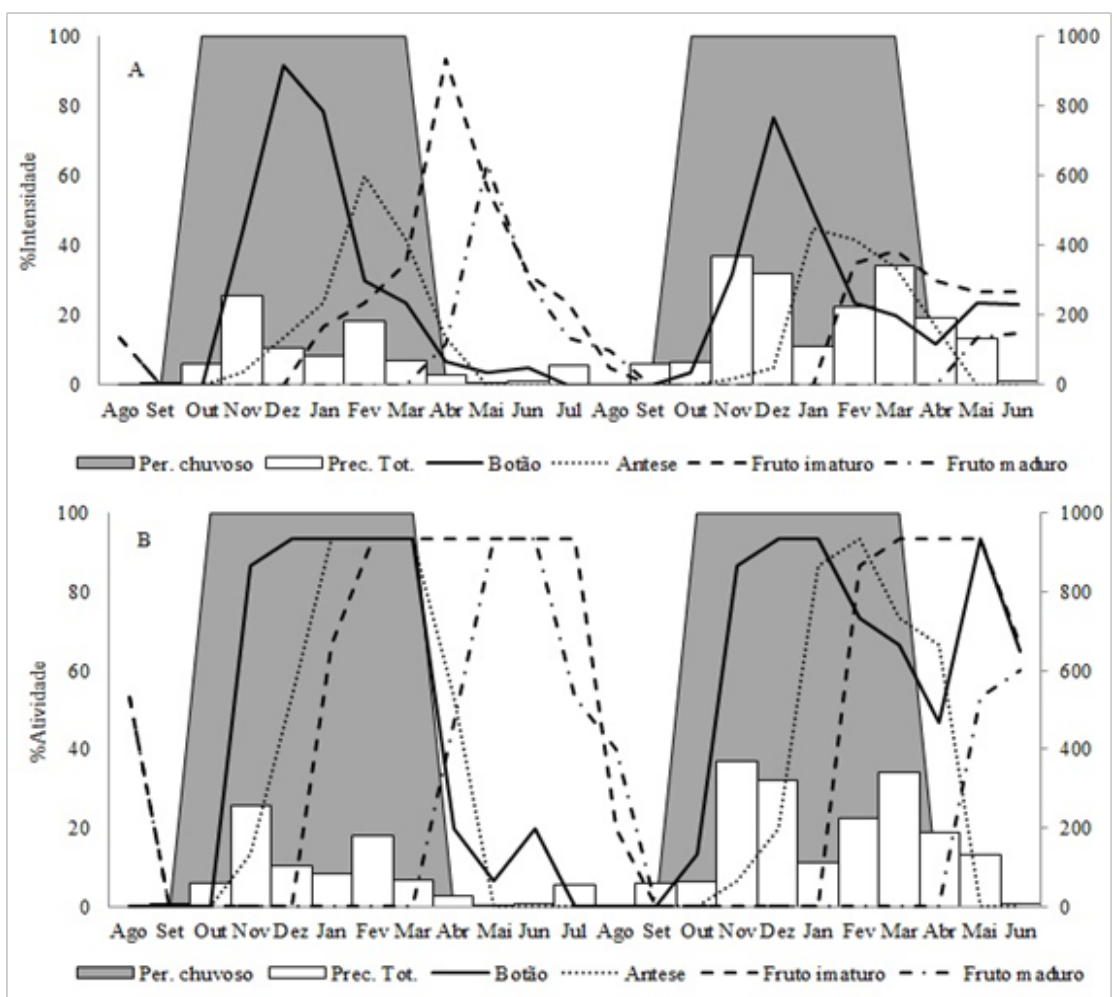

Figura 1. Fenologia de B. basiloba. (A) Índice de intensidade de Fournier dos eventos reprodutivos e (B) Porcentagem de indivíduos (atividade) nos eventos reprodutivos do período de agosto de 2013 a junho de 2015.

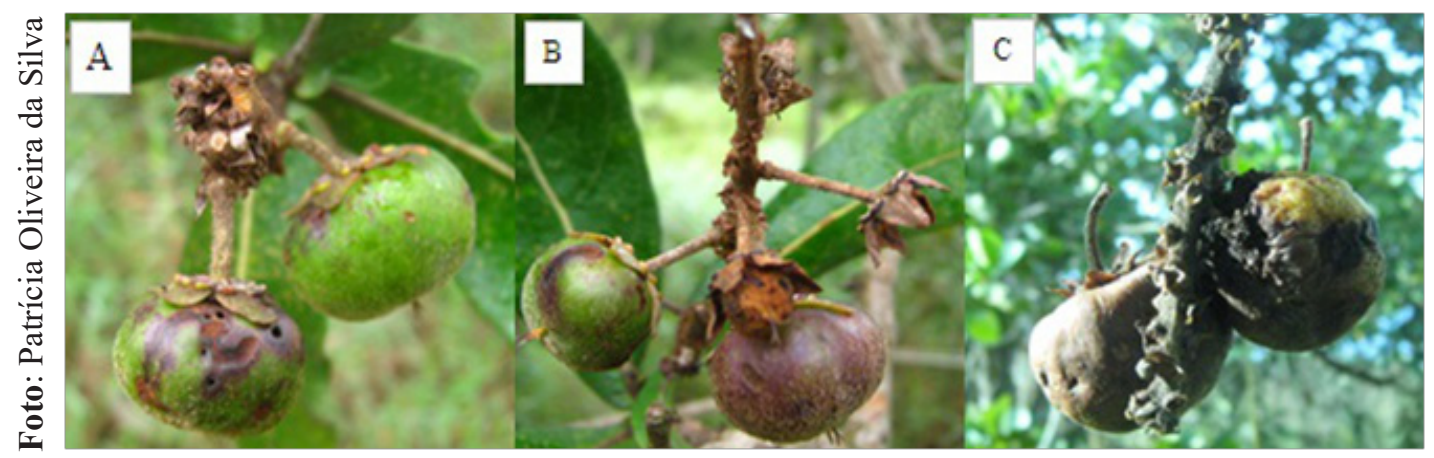

Figura 2. Frutos imaturos de B. basiloba com vários orifícios (A); fruto seco e fruto imaturo manchado (B) e frutos com sinais de predação, podres e fixos à planta-mãe (C).

Os frutos de B. basiloba começaram a amadurecer na transição do período chuvoso para o seco, embora as maiores concentrações tenham sido observadas na época de menor pluviosidade (Figura 1-A). Os picos do evento de fruto maduro foram observados em maio e em junho para 2014 e 2015, respectivamente. A alta sincronia para esta fenofase foi observada nos meses de menor índice de pluviosidade (Figura 1-B). A intensidade de frutos maduros foi consideravelmente baixa, principalmente a de 2015, ano que se observou maior quantidade de frutos danificados. A maturação dos frutos ocorreu durante a estação mais seca do ano e culminou em correlações significativamente negativas com todos os fatores climáticos da área de estudo (Tabela 1). Após a frutificação, poucos frutos permaneceram presos e com aspecto mumificado, secos e duros. Segundo Sano (2004), são poucas as espécies que apresentam frutos com polpa carnosa durante a estação seca no Cerrado, como o baru. Essas espécies são importantes para alimentação da fauna nessa época, incluindo tanto os morcegos que retiram os frutos das árvores para consumir a polpa, quanto primatas que consomem tanto 
a polpa quanto as sementes. E diante dos resultados obtidos por este estudo, pode-se afirmar que B. basiloba está entre estas espécies.

Durante o período de menor precipitação e início da época chuvosa registrou-se o evento de senescência, entretanto, as maiores concentrações ocorreram após o mês mais seco do ano (Figura 3-A), o que culminou na correlação negativa com a precipitação da área de estudo (Tabela 1). O evento foi muito sincrônico de agosto a outubro de 2013, junho e setembro de 2014 e abril e junho de 2015 (Figura 3-B). Araújo et al. (2014) registraram comportamento semelhante ao de B. basiloba em $B$. verbascifolia no nordeste brasileiro. Morellato (1991) afirma que a deciduidade foliar representa uma adaptação vegetativa, principalmente contra a perda de água e também para a sobrevivência de espécies por um período desfavorável, corroborando com os dados obtidos ao afirmar que o principal fator na influência dos padrões fenológicos das espécies tropicais é a precipitação, principalmente em florestas tropicais com estações bem definidas e sazonalmente evidentes na precipitação anual, como é o caso da região onde se desenvolveu este estudo.

A emissão de brotos foi observada juntamente com a senescência, ocorrendo em meados do período seco, transição do período seco para o chuvoso e durante a época chuvosa (Figura 3-A). O pico ocorreu em setembro de 2014 e outubro de 2015, entretanto, a intensidade foi inferior a $40 \%$. Observou-se que o evento foi muito sincrônico em setembro e outubro de 2014 e setembro, outubro e novembro do ano seguinte (Figura 3-B). A brotação apresentou correlação significativamente positiva com a temperatura da área estudada (Tabela 1). Essa correlação parece ser bastante comum, sendo rpor Pirani et al. (2009), Soares et al. (2013) e Faria et al. (2015) resultados semelhantes ao estudo. O aumento de fotoperíodo e elevação da temperatura podem ser fatores indutores do brotamento de árvores tropicais, por meio da estimulação do desenvolvimento de brotos apicais (Morellato, 1991).

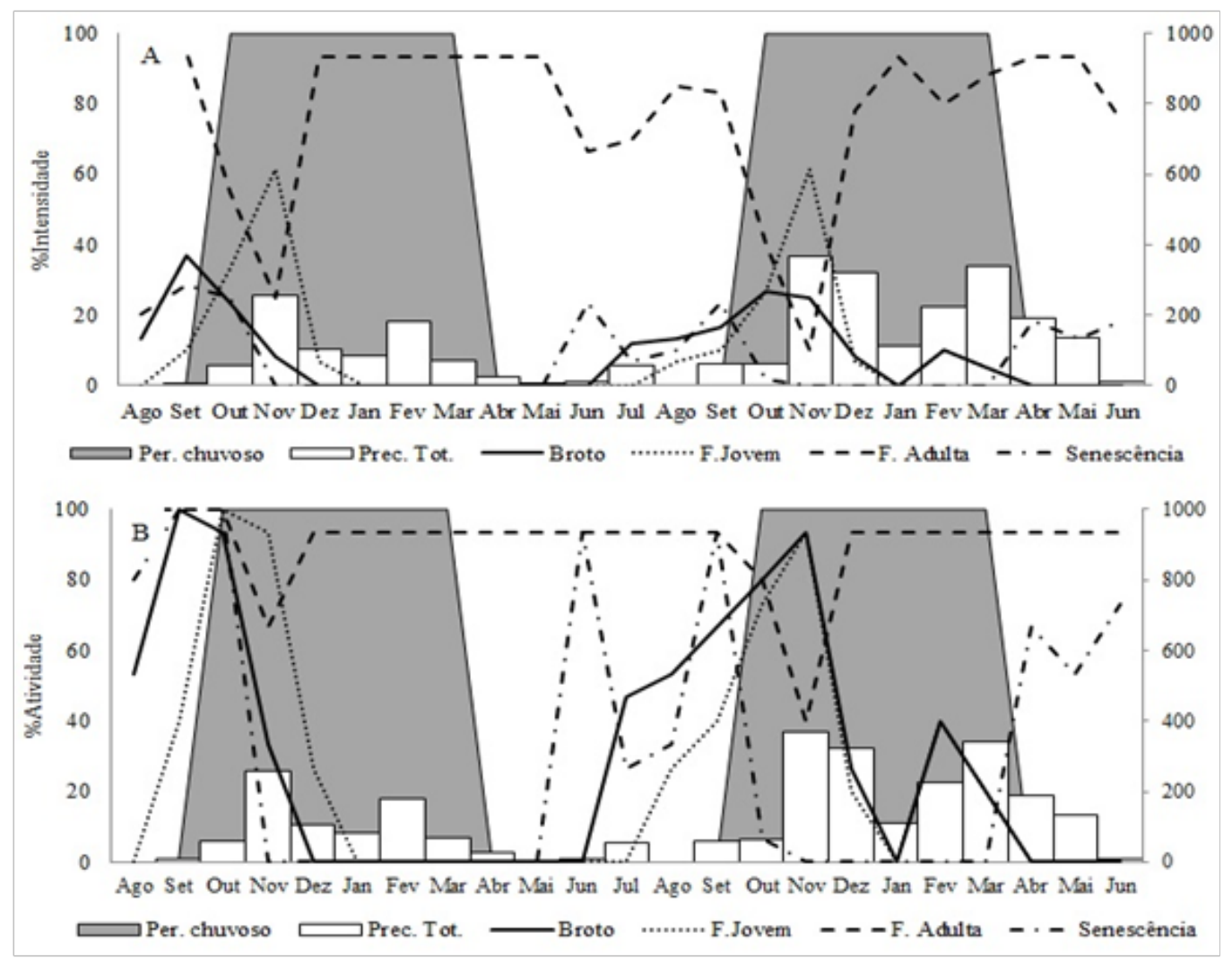

Figura 3. Fenologia de B. basiloba. Índice de intensidade de Fournier dos eventos vegetativos (A) e porcentagem de indivíduos (atividade) nos eventos vegetativos (B) do período de agosto de 2013 a junho de 2015. 
A fenofase de folhas jovens foi registrada no último mês da estação seca e primeiros meses da chuvosa (Figura 3-A). O pico ocorreu em novembro, mês que apresentou o maior índice pluviométrico durante o estudo, resultando na correlação positiva com precipitação e temperatura (Tabela 1). Barbosa et al. (2005) encontraram em $B$. crassifolia e $B$. coccolobifolia em área de savana aberta respostas semelhantes ao observado em $B$. basiloba nesse trabalho, confirmando a associação entre as fenofases e regime de precipitação. De acordo com Morellato et al. (1989), o padrão apresentado por essas espécies é perenifólio, uma vez que produzem de forma intermitente baixa quantidade de folhas novas logo após a queda das folhas maduras, mantendo-se sempre enfolhadas, sem a dormência típica das plantas caducifólias. Houve alta sincronia em outubro e novembro para ambos os anos de observação. Segundo Souza et al. (2014), o fato das espécies apresentarem alto sincronismo na produção de folhas novas pode ser atribuído à disponibilidade hídrica, por meio da precipitação no início da estação chuvosa, pois todas as espécies, tanto as decíduas quanto as perenes aguardam por essa disponibilidade para ativar seus mecanismos de produção foliar, pelo menos de forma mais intensa.

A folhagem adulta foi observada durante todos os meses de acompanhamento (Figura 3-A). A menor intensidade foi registrada no mês de maior concentração de folhas jovens, mais especificamente no mês de maior índice pluviométrico e umidade, o que levou à correlação negativa com estes fatores climáticos (Tabela 1). O evento foi muito sincrônico em todos os meses de observação, exceto em novembro de 2015, pois apenas $10 \%$ dos indivíduos estavam manifestando a fenofase (Figura 3-B). Segunda Maia (2004), existe uma tendência de que espécies arbóreas de ambientes mais secos, não apenas da vegetação do Cerrado, mas também da Caatinga, apresentem seus eventos fenológicos vegetativos controlados principalmente pela precipitação (Dutra, 1987).

\section{Conclusão}

O comportamento reprodutivo de Byrsonima basiloba é distinto de algumas espécies do mesmo gênero, mas semelhante a outras espécies do Cerrado. No entanto, os aspectos vegetativos são comuns não só a outras espécies, mas também de Byrsonima spp.
As fenofases reprodutivas de $B$. basiloba são influenciadas pela precipitação, temperatura e umidade da área de estudo, entretanto, a precipitação causa um efeito positivo, enquanto que o efeito negativo é causado pela temperatura e umidade. Para os eventos vegetativos, esses dois fatores climáticos promovem mais influência negativa do que positiva sobre $B$. basiloba.

\section{Referências}

Anderson, W. R. Floral conservation in neotropical Malpighiaceae. Biotropica, v. 11, n. 2, p. 219-223, 1979. DOI: 10.2307/2388042.

Araújo, R. R. et al. Fenologia do muricizeiro Byrsonima verbascifolia (L.) Rich em zona de tabuleiro costeiro do Nordeste brasileiro. Revista Ciência Agrícola, v. 12, n. 1, p. 1-8, 2014.

Barbosa, R. I. et al. Fenologia do mirixi-caju Byrsonimia coccolobifolia Kunth. (Malpighiaceae) em áreas de savana aberta do Estado de Roraima. Boa Vista: Embrapa Roraima, 2005. 6 p. (Embrapa Roraima. Comunicado técnico, 13).

Batalha, M. A. \& Mantovani, W. Reproductive phenological patterns of Cerrado plant species at the Pé-de-Gigante Reserve (Santa Rita do Passa Quatro, SP, Brasil): a comparison between the herbaceous and woody floras. Revista Brasileira de Biologia, v. 60, n. 1, p. 129-145, 2000. DOI: $10.1590 / \mathrm{S} 0034-71082000000100016$.

Bencke, C. S. C. \& Morellato, L. P. C. Comparação de dois métodos de avaliação da fenologia de plantas, sua interpretação e representação. Revista Brasileira de Botânica, v. 25, n. 3, p. 269-75, 2002. DOI: 10.1590/S0100-84042002000300003.

Benezar, M. C. \& Pessoni, L. A. Biologia floral e sistema reprodutivo de Byrsonima coccolobifolia (Kunth) em uma savana amazônica. Acta Amazônica, v. 36, n. 2, p. 159-168, 2006. DOI: 10.1590/ S0044-59672006000200005.

Bezerra, E. S. et al. Biologia reprodutiva de Byrsonima gardneriana A. Juss. (Malpighiaceae) e interações com abelhas Centris (Centridini) no Nordeste do Brasil. Revista Brasileira de Botânica, v. 32, n. 1, p. 95-108, 2009. DOI: 10.1590/S0100-84042009000100010.

Dutra, R. C. Fenologia de dez espécies arbóreas nativas do Cerrado de Brasília-DF. Brasil Florestal, v. 62, n.1, p. 23-41, 1987.

Faria, R. A. P. G. et al. Fenologia de Brosimum gaudichaudii Trécul. (Moraceae) no Cerrado de Mato Grosso. Ciência Florestal, v. 25, n. 1, p. 67-75, 2015. DOI: 10.1590/10.1590/1980-509820152505067.

Farias, R. et al. Caminhando pelo Cerrado: plantas herbáceas arbustivas: caracteres vegetativos e organolépticos. Brasília, DF: Ed. da UnB, 2002. 94 p.

Figueiredo, P. S. de. Fenologia e estratégia reprodutivas das espécies arbóreas em uma área marginal de Cerrado, na transição para o semiárido no Nordeste do Maranhão, Brasil. Revista Trópica: Ciências Agrárias e Biológicas, v. 2, n. 2, p. 8-22, 2008.

Fournier, L. A. \& Charpantier, C. El tamaño de la muestra y las observaciones en el estudio de características seasons in a tropical forest. Turrialba, v. 25, n. 1, p. 45-48, 1975. 
Fournier, L. A. Un método cuantitativo para la medición de características fenológicas en árboles. Turrialba, v. 24, n. 4, p. 422-3, 1974.

Freitas, V. G. et al. Fenologia de Caryocar brasiliense Camb. (Caryocaraceae) no Alto Rio Grande, sul de Minas Gerais. Cerne, v. 14, n. 4, p. 317-329, 2008.

Haridasan, M. Solos do Distrito Federal. In: Novais-Pinto, M. (Org.). Cerrado: caracterização, ocupação e perspectivas. Brasília, DF: UnB. 1993, p. 309-30.

Instituto Nacional de Meteorologia. Estações automáticas: Estação Rio Verde (A025). Disponível em: <http://www.inmet.gov.br/portal/ index.php? $\mathrm{r}=$ home/page\&page $=$ rede_estacoes_auto_graf $>$. Acesso em: 20 jul. 2015.

Judd, W. S. et al. Plant Systematics: a phylogenetic approach. Sunderland: Sinauer Associates, 2002. 576 p.

Lorenzi, H. Árvores brasileiras: manual de identificação e cultivo de plantas arbóreas nativas do Brasil. Nova Odessa: Instituto Plantarum, 2008. 238 p.

Maia, G. N. Caatinga: árvores e arbustos e suas utilidades. São Paulo: D\&Z, 2004. 415 p.

Medeiros, J. D. Guia de campo: vegetação do Cerrado 500 espécies. Brasília, DF: Ministério do Meio Ambiente, Secretaria de Biodiversidade e Florestas, 2011. 532 p. (Série Biodiversidade, 43). Disponível em: <http://www.mma.gov.br/estruturas/sbf2008 df/_publicacao/148_publicacao14022012101832>. Acesso em: $1 \overline{0}$ jul. 2015.

Mendonça, R. C. et al. Flora vascular do Cerrado. In: Sano, S. M. \& Almeida, S. P. (Ed.). Cerrado: ambiente e flora. Planaltina, DF: Embrapa-CPAC, 1998, p. 288-556.

Morellato, L. P. C. et al. Estudo comparativo da fenologia de espécies arbóreas de floresta de altitude e floresta mesófila semidecídua na Serra do Japí, Jundiaí, São Paulo. Revista Brasileira de Botânica, v. 12, n. 1, p. 85-98, 1989.

Morellato, L. P. C. Fenologia de árvores, arbustos e lianas em uma floresta semidecidual no Sudeste do Brasil. 1991. Tese (Doutorado em Ecologia) -Universidade de Campinas, Campinas.

Newstrom, L. E. et al. Diversity of long-term flowering patterns. In: McDade, L. A. et al. (Ed.). La Selva: ecology and natural history of a neotropical rain forest. Chicago: University of Chicago Press, 1994. p. 142-160.

Oliveira, H. V. Associação entre drosofilídeos (Insecta: Díptera) e frutos como sítios de criação larval. 2013. 162 f. Dissertação (Doutorado em Ecologia) - Instituto de Biologia da Universidade de Brasília, Brasília, DF.

Oliveira, M. I. B. \& Sigrist, M. R. Fenologia reprodutiva, polinização e reprodução de Dipteryx alata Vogel (Leguminosae-Papilionoideae) em Mato Grosso do Sul, Brasil. Revista Brasileira de Botânica, v. 31, n. 2, p. 195-207, 2008. DOI: 10.1590/S0100-84042008000200002.

Oliveira, P. E. Fenologia e biologia reprodutiva das espécies de Cerrado. In: Sano, S. M. et al. (Ed.). Cerrado: ecologia e flora. Brasília, DF: Embrapa Informação Tecnológica; Planaltina, DF: Embrapa Cerrados, 2008. p. 273-290.
Pereira, J. O. P. \& Freitas, B. M. Estudo da biologia floral e requerimentos de polinização do muricizeiro (Byrsonima crassifolia L.). Revista Ciência Agronômica, v. 33, n. 2, p. 5-12, 2002.

Pirani, F. R. et al. Fenologia de uma comunidade arbórea em cerrado sentido restrito, Barra do Garças, MT, Brasil. Acta Botânica Brasílica, v 23, n. 4, p. 1096-1109, 2009. DOI:10.1590/S010233062009000400019 .

Ribeiro, J. E. L. S. et al. Flora da Reserva Ducke: guia de identificação das plantas vasculares de uma floresta de terra-firme na Amazônia Central. Manaus: INPA, 1999. 816 p.

Rosa, J. F. \& Ramalho, M. Sucesso reprodutivo de Byrsonima sericea DC. (Malpighiaceae) e diversidade de abelhas Centridini (Apidae). Revista Brasileira de Biociência, v. 5, n. 1, p. 168-170, 2007.

Sano, S. M. Baru: biologia e uso. Planaltina, DF: Embrapa Cerrados, 2004. 52 p.

Silva, C. I. et al. Distribuição vertical dos sistemas de polinização bióticos em áreas de Cerrado sentido restrito no Triângulo Mineiro, MG, Brasil. Acta Botânica Brasílica, v. 26, n. 4, p. 748-760, 2012. DOI: 10.1590/S0102-33062012000400004.

Silvério, D. V. \& Fernandes-Bulhão, C. Fenologia reprodutiva e biometria de frutos e sementes de três espécies de Byrsonima Rich. ex Kunth (Malpighiaceae) no Parque do Bacaba, Nova Xavantina Mato Grosso. Revista de Biologia Neotropical, v. 6, n. 1, p. 55-73, 2009. DOI: 10.5216/rbn.v6i1.12629.

Soares, M. P. et al. Aspectos fenológicos de Xylopia aromatica (Lam.) Mart. (Annonaceae) em vegetação de Cerradão, Goiás, Brasil. Bioikos, v. 28, n. 2, p. 65-71, 2014.

Soares, M. P. et al. Fenologia de Annona coriacea Mart. (Annonaceae) em um Fragmento de Cerrado sensu stricto em Rio Verde, Goiás. Revista do Instituto Florestal, v. 25, n. 1 p. 107-113, 2013.

Souza, D. N. N. et al. Estudo fenológico de espécies arbóreas nativas em uma unidade de conservação de caatinga no Estado do Rio Grande do Norte, Brasil. Biotemas, v. 27, n. 2, p. 31-42, 2014. DOI: $10.5007 / 2175-7925.2014 \mathrm{v} 27 \mathrm{n} 2 \mathrm{p} 31$.

Souza, V. C. \& Lorenzi, H. Botânica sistemática: guia ilustrado para identificação das famílias de fanerógamas nativas e exóticas no Brasil, baseado em APG II. Nova Odessa: Instituto Plantarum, 2008. v. 1.704 p.

Tabarelli, M. Fenologia das espécies arbóreas de Mata Serrana (Brejos de altitudes) em Pernambuco, Brasil. In: Pôrto, K. C. et al. (Org.). Brejos de altitude em Pernambuco e Paraíba: história natural, ecologia e conservação. Brasília, DF: Ministério do Meio Ambiente: Universidade Federal de Pernambuco, 2004. p. 255-276. (Série Biodiversidade, 9).

Teixeira, L. A. G. \& Machado, I. C. Sistema de polinização e reprodução de Byrsonima sericea DC (Malpighiaceae). Acta Botânica Brasílica, v. 14, n. 3, p. 347-357, 2000. DOI: 10.1590/ S0102-33062000000300011. 
